\title{
O DESENHO E SUAS RELAÇÕES COM A LINGUAGEM ESCRITA EM ALUNOS PORTADORES DE DEFICIÊNCIA MENTAL
}

\section{Wanda Pereira Patrocinio}

\section{INTRODUÇÃO}

O presente trabalho nasceu de uma pesquisa de sondagem sobre a aprendizagem da linguagem escrita em deficientes mentais, na qual verificou-se que essas crianças, em alguns momentos, desenhavam ao invés de escrever. Essa investigação vem, também, preencher uma lacuna, pois notamos a escassez de trabalhos sobre o desenho de crianças deficientes.

Para Vygotsky, o desenho deve ser interpretado como um estágio preliminar do desenvolvimento da linguagem escrita, estágio este entendido mais do que como uma simples antecedência temporal.

Mesmo que nossa pesquisa esteja voltada para crianças “deficientes mentais", é relevante percebermos como a deficiência é enfocada; não se pode considerar $\mathrm{o}$ deficiente mental como uma pessoa apenas receptora mecânica de conhecimento que os outros possuem, sem nunca ter participado da construção de qualquer saber. É preciso considerar este aluno como um ser que age, decide e pensa por seus próprios meios, principalmente ao trabalharmos na perspectiva da teoria histórico - cultural, que considera que o indivíduo (normal ou deficiente) é constituído pela/na trama de relações sociais.

A tese que fundamenta os trabalhos da Defectologia (VYGOTSKY, 1989) é a de que a criança, cujo desenvolvimento tem sido complicado por um defeito, não é sensivelmente menos desenvolvido que seus coetâneos normais, é uma criança, porém desenvolvido de outro modo.

A perspectiva vygotskyana analisa a questão da deficiência de forma qualitativa e não mais meramente quantitativa. Dessa maneira, a criança, em cada etapa do desenvolvimento, em cada fase sua, apresenta uma peculiaridade qualitativa, uma estrutura específica do organismo e da personalidade; a criança com deficiência representa um tipo peculiar, qualitativamente distinto de desenvolvimento. GÜTLER (1927) afirma que a deficiência mental infantil deve ser encarada como uma variedade singular, como um tipo especial de desenvolvimento e não como uma variante quantitativa do tipo normal.(In VYGOTSKY, 1989: 03)

\section{2) OBJETIVOS:}

Tivemos como propósitos neste trabalho:

- Buscar uma melhor compreensão do desenho produzido por crianças portadoras de deficiência mental.

- Dar oportunidades para que o desenho se manifestasse e se elaborasse nessas crianças. 
- Observar os processos espontâneos de utilização do desenho por tais alunos.

- Confrontar o material gráfico destes sujeitos com sua produção escrita com o intuito de investigar as possíveis relações existentes entre desenho e linguagem escrita.

\section{3) MATERIAIS E MÉTODOS:}

Foram realizadas observações semanais $^{1}$ do material produzido pelos alunos de uma classe especial de uma escola estadual na cidade de Campinas, empregando como forma de trabalho a análise qualitativa. Outra parte da pesquisa foi desenvolvida dentro da rede de bibliotecas da Universidade Estadual de Campinas.

Para compor os dados, além das leituras e observações, levamos atividades que propiciaram aos alunos a elaboração e manifestação do desenho como uma forma de linguagem; demos ênfase aos trabalhos de dois sujeitos: um alfabetizado, mas que não gostava de desenhar e outro que desenhava bem, mas que não sabia escrever.

\section{4) RESULTADOS E DISCUSSÃO:}

Para análise das produções gráficas dos sujeitos, levamos em consideração alguns aspectos que nortearam o andamento de nosso trabalho:

- A visão genética ou desenvolvimentista do desenho: estágios e fases;

- Fala egocêntrica e fala social no processo de produção do desenho;

- A relação entre desenho e escrita;

- A concepção de "savant" relacionado ao desenho (cf. página 9)
4.1) A visão genética ou desenvolvimentista do desenho: estágios e fases.

VYGOTSKY (1987) afirma que as etapas através das quais as crianças passam em seus desenhos são mais ou menos comuns para as crianças da mesma idade. Tanto este autor como muitos outros fizeram uma descrição da evolução do desenho em crianças normais. Até o momento não encontramos nenhum autor que tratasse da evolução do desenho de crianças deficientes mentais, mas REILY (1986) utiliza-se dos estudos de Lowenfeld \& Kellog (que por sua vez, se basearam nos trabalhos de Luquet) para descrever os estágios pelos quais a criança passa no desenho, enfatizando o que ocorre em crianças deficientes.

São cinco fases existentes na evolução do desenho, "no caso da criança excepcional, pode haver um desenvolvimento artístico mais lento, como também pode ocorrer um estacionamento em algum estágio, sem progresso aparente." (REILY, 1986: 12-13)

As fases são: garatuja, pré esquemática, esquemática, realismo visual e naturalista. A primeira fase é a fase dos rabiscos, quando a criança explora livremente o espaço do papel, rabiscando não por motivos estéticos, mas por prazer cinético. No início seus rabiscos são descontrolados, muitas vezes, sem focalização visual do papel; num certo momento, a criança descobre que os riscos são feitos por ela própria, começando a se concentrar na atividade com interesse renovado, passando a controlar seus rabiscos.

\footnotetext{
${ }^{1}$ No período julho/99 - julho/2000.
} 
A criança não passa diretamente do rabisco ao desenho do homem cabeça pernas. Ela desenvolve do rabisco descontrolado ao rabisco controlado, do rabisco nomeado ao rabisco em formato, da forma com um traço até a junção das formas descobertas. A criança deficiente, ainda segundo Reily, pode ficar muito tempo nesta fase dos rabiscos e, se o professor não conhece a evolução que acontece nesta fase, ele não vai saber reconhecer o desenvolvimento que a criança está tendo.

$\mathrm{Na}$ fase pré - esquemática ocorre o processo de junção das formas, a criança descobre a "mandala": círculos concêntricos, círculos cruzados, até quadrados cruzados, figuras perfeitamente simétricas. Aparece o asterisco: o sol, que é a primeira simbolização da criança. É assim que surgem, como uma elaboração da mandala, o homem, os animais e as flores.

Fase esquemática: o esquema é a forma humana que a criança escolhe como seu desenho definitivo, que ela vai usar daquele momento em diante, modificando-o apenas quando as circunstâncias o exigem. Este esquema é muito individualizado, pois cada criança descobre o seu. A grande mudança da fase anterior está na representação do espaço; as figuras não são mais colocadas aleatoriamente no papel, mas num conjunto inter - relacionado, sendo a primeira indicação desta evolução a linha de base, que pode ser o chão, a rua, água do mar ou um morro e tudo fica em cima desta linha base, perpendicular a ela; o céu também é representado como uma linha que fica na parte superior da folha.

O desenho desta fase é muito pessoal, retratando as experiências que são relevantes para a criança, mas REILY (1986) coloca que, dificilmente a criança excepcional deficiente mental ultrapassa esta fase esquemática para atingir as fases seguintes. A autora continua citando que é difícil encontrar uma criança excepcional, mesmo de "nível educável" (conceito utilizado pela autora), que tenha alcançado o nível de elaboração artística da fase do realismo visual, principalmente quando não houve quase oportunidade para o seu desenvolvimento artístico. Esta fase caracteriza-se pela riqueza de detalhe e a preocupação em representar os objetos realisticamente. A criança não exagera mais nem omite partes menos importantes, mas elabora essas partes através de detalhes. Para representar espaço, ela se apoia em uma linha de base, preenchendo a área em baixo e trazendo o céu até o chão. Cria planos e os sobrepõe, para mostrar o que está na frente. $\mathrm{O}$ sistema de dobragem e raio - x são considerados absurdos nesta fase $\mathrm{e}$ não aparecem mais; a cor assume uma importância renovada, mas ainda não se trabalha luz e sombra, nem efeitos tridimensionais. A criança procura novas formas e não repete mais o seu velho esquema corporal.

Fase naturalista: nessa fase, a temática utilizada por cada sexo - meninos e meninas passam a se diferenciar; os meninos passam a desenhar mais coisas mecânicas, como foguetes, carros, fábricas, etc., enquanto meninas desenham animais, principalmente o cavalo e figuras humanas. A figura humana passa a ter proporções adequadas; a criança começa a desenhar a figura em movimento, retratando inclusive as articulações dos membros - braços, pernas - pela primeira vez.

Já que a autora faz referência aos estágios percebidos por Luquet, consideramos relevante colocar uma citação deste teórico, citação esta, que a nosso ver, tem relação principalmente com o processo 


\section{ARTIGO EM TCC}

de evolução do desenho em crianças portadoras de deficiência mental: "A evolução individual do desenho, como todas as modificações de atividade, está sujeita a regressões." (LUQUET, 1969: 212). Se essa afirmação é válida mesmo para as crianças ditas "normais", veremos que entre nossos sujeitos também encontramos momentos em que surgem tais regressões.
Embora esse aspecto desenvolvimentista não tenha merecido uma importância fundamental em nossas análises, parece-nos interessante apresentar dois desenhos que por suas características se enquadrariam dentro do realismo visual, indicando também alguns traços típicos do naturalismo.

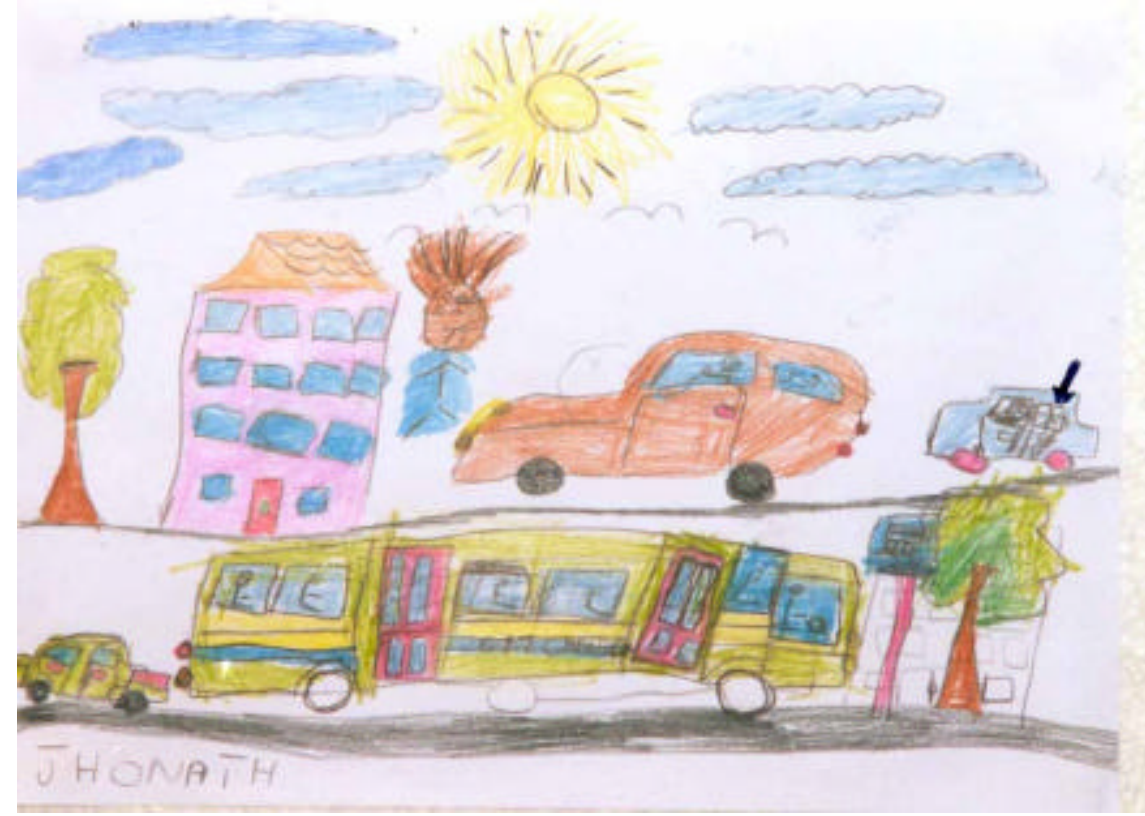




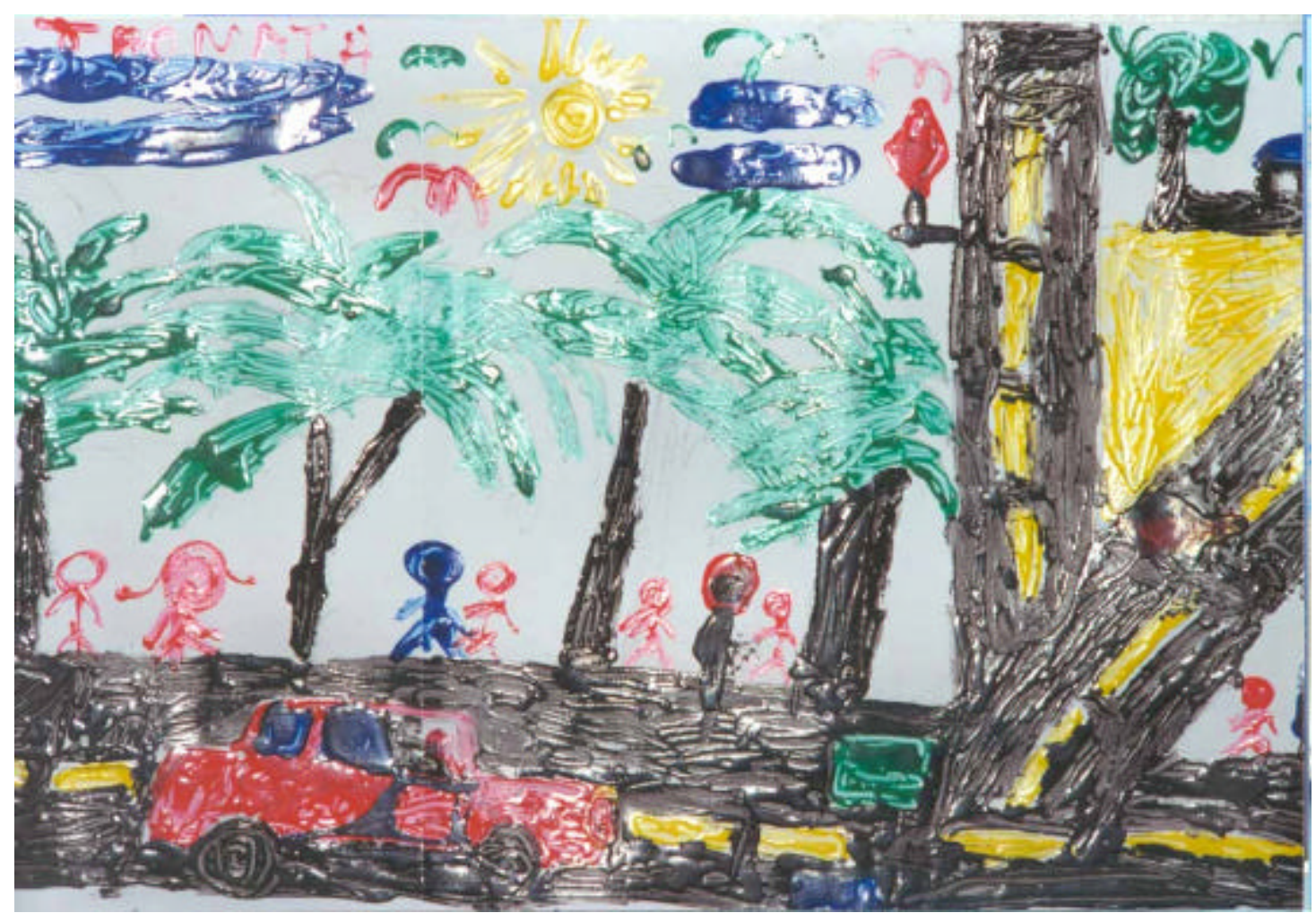

4.2)Fala egocêntrica e fala social no processo de produção do desenho.

SILVA (1993) afirma, que a perspectiva histórico - cultural "possibilita ver o desenho como um signo empregado pelo homem e constituído a partir das interações sociais." (p. 11). Além disso, as teses dessa teoria apontam para a necessidade de se examinar o desenho a partir de outros ângulos, entre os quais, a relação estabelecida com a fala. "Importa considerar tanto a fala auto organizadora quanto a fala nas trocas dialógicas, que permeiam a atividade da criança e que tem sido negligenciada na análise do desenho." (idem: 18).

VYGOYSKY (1993) vai tratar da fala egocêntrica de uma forma mais geral nas atividades da criança, porém ela será compreendida, para nosso caso específico, como relevante na atividade de desenho: “... tal fala vai, progressivamente, tornando-se apropriada para planejar e resolver problemas, à medida que as atividades da criança tornam-se mais complexas. Esse processo é desencadeado pelas ações da criança; os objetos com os quais ela lida, representam a realidade e dão forma aos seus processos mentais." (p. 20)

Em uma perspectiva diferente da de Vygotsky e sem relação com a fala egocêntrica, WIDLÖCHER (1990) também considera a questão da fala no momento da produção do desenho; ele afirma que observar a criança desenhar e escutar seus comentários enquanto desenha, nos permite penetrar em todo um campo de conexões associativas, semânticas e afetivas, que o 
simples diálogo raramente dá ocasião de apreender.

O que pudemos notar, ao final deste trabalho, é que não surgiu esta fala egocêntrica citada pelos autores acima. Todos os trabalhos teóricos aos quais tivemos acesso e que tratam da questão da fala egocêntrica enquanto as crianças estão desenhando, estão relacionados às crianças normais; VYGOTSKY (1987) afirma que de todas as formas de criação literária, a arte da palavra, do falar é mais típica da idade escolar.

Todavia, nos momentos de observação, não foi notado a presença da fala egocêntrica; quando os alunos falavam durante $o$ processo de produção do desenho, exigiam a atenção do outro, sua fala estava sempre voltada para o outro que interagia com ele naquele momento. Quem sabe, até, podemos considerar esta ocorrência como uma singularidade dos alunos portadores de deficiência mental: a ausência de fala egocêntrica e uma plena utilização da fala social. Talvez haja algo mais a ser pesquisado e aprofundado neste sentido, em trabalhos futuros.

\section{3) A relação entre desenho e escrita.}

Reily, em sua Dissertação de Mestrado, cita que existe uma estreita ligação entre o desenho e a escrita. Ambos são meios de expressão e comunicação, determinados por habilidades próximas de motricidade e pensamento simbólico. “ $\mathrm{O}$ desenho, todavia, possibilita uma leitura que ultrapassa a linguagem individual de cada um, ao passo que a escrita é dependente da linguagem." (REILY, 1990: 66)
Em entrevista com a professora Ana Angélica Albano Moreira ${ }^{2}$, ela acrescenta que no desenho tudo subsiste ao mesmo tempo: "em apenas um olhar você enxerga tudo, já no texto escrito, você tem que ler palavra por palavra para poder entender". Em suma, há uma simultaneidade na percepção dos elementos do desenho contraposta à linearidade da fala e da escrita.

MEREDIEU (1974) também trata da função simbólica no desenvolvimento da criança, afirmando que a evolução do desenho depende intimamente da evolução da linguagem e da escrita, pois "é uma parte atraente do universo adulto, dotada de prestígio por ser secreta, a escrita exerce uma verdadeira fascinação sobre a criança, e isso bem antes de ela própria poder traçar verdadeiros signos." (p. 9)

Entretanto, encontramos uma afirmação de Harste e colaboradores que questiona a visão corrente que afirma ser o desenho nascido antes da escrita. Esses autores "consideram que há uma relação recíproca, de apoio mútuo, na atuação da criança ao desenhar e aprender a escrever." (In REILY, 1990: 67)

AZENHA (1995) pesquisou os fatores que explicam a ocorrência e o movimento dos processos de diferenciação gráfica, ensaiando explicações que buscassem continuidades funcionais entre os rabiscos e as primeiras formas de organizar diferenciações decorrentes da compreensão da escrita como signo cultural. Segundo a autora, no período que corresponde à pré história, reencontramos a mesma evolução na forma de usar imagens com fins de escrita, que, neste caso, sofrem o mesmo

\footnotetext{
${ }^{2}$ Profa. Dra. da Faculdade de Educação da Universidade Estadual de Campinas, Laboratório de Arte - Educação.
} 
processo de simplificação realizado pelas crianças analisadas em seu estudo. A esquematização do desenho e seu conseqüente afastamento da imagem visual do objeto é também característico da história da escrita neste período primitivo. (Ver quadro a página 10 e o que a autora escreve a respeito).

Em relação à afirmação de Harste e colaboradores, parece-nos que Azenha vem concordar com eles quando cita que, "desenho e escrita parecem ocupar lugares complementares na produção gráfica e a imagem não aparece paralela à escrita apenas para garantir a evocação dos significados às quais esta se refere. Desenho e escrita "dizem" um em relação ao outro e não são redundantes." (1995:175)

\section{Para completar WIDLÖCHER} (1971) assinala que "historicamente a escrita nasceu de um encontro entre a coisa desenhada e a palavra." (p. 77)

Através dos dados teóricos pode-se dizer que, historicamente, o desenho nasceu primeiro que a escrita. Nos primórdios, os homens usavam o desenho como meio de memorização e organização; a escrita cuneiforme surgiu dos signos que representavam determinados elementos. (cf. Quadro da página 10)

Para nós, é factual que a criança primeiro começa a desenhar e, ao longo de seu desenvolvimento, vai aprendendo a linguagem escrita, mas não podemos considerar o desenho como estágio preliminar, pois são linguagens que se complementam e, em muitos casos, se completam. Se o desenho fosse um estágio preliminar para a ocorrência da escrita, então como se explicaria o caso de nossos dois sujeitos? Por um lado, o Lu., cujas produções são muito primitivas; se realmente considerássemos o desenho como estágio preliminar, este aluno ainda não teria condições de escrever, e no entanto, é um aluno praticamente alfabetizado. Por outro lado, temos o Jo., que apresenta desenhos riquíssimos em detalhes e cores; deveria saber escrever muito bem, o que não ocorre. (Ver desenho de Jo na página 11 e de Lu. na página 12.)

Por esses exemplos, notamos que mesmo aceitando que na história da humanidade, o desenho precede a escrita, essa seqüência não ocorre, necessariamente, no nível ontogenético.

\section{4) A concepção de "savant"} relacionado ao desenho.

Para HILL (1978), "savant" é "uma pessoa mentalmente retardada demonstrando uma ou mais habilidades acima do nível esperado de indivíduo não retardado." (In REILY, 1994: 17). Utilizase, portanto, o termo savant para: "pessoas que têm apresentado habilidades extraordinárias em áreas específicas do desempenho humano.” (REILY, 1994: 21) 
Um exemplo que fala por si é a análise da transformação sofrida pelos primitivos signos icônicos que estavam na base - da escritâ cunęiforme e que, paulatinamente, afastam-se dos primitivos desenhos para, na forma final, estarem tão convencionalizados que sua origem icônica é irreconhecível, como se vê na figura a seguir.

\begin{tabular}{|c|c|c|c|c|}
\hline PÁJARO & $\mathcal{d}$ & 8 & $+V$ & Fit \\
\hline PEZ & & & & Fis \\
\hline ASNO & & & 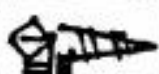 & $\rightarrow=$ \\
\hline BUEY & & & & $H_{4}^{4}$ \\
\hline SOL & $\infty$ & 8 & & $\Delta$ \\
\hline GRANO & & W & & $x$ \\
\hline HUERTO & 题 & ${ }_{m-1}^{m-1}$ & & 击四 \\
\hline ARADO & $m$ & & & 東 \\
\hline BUMERANG & $\approx$ & $D$ & & AIII \\
\hline PIE & D & 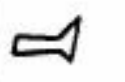 & & 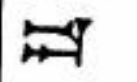 \\
\hline
\end{tabular}

Origem pictorica de dez signos cuneiformes

A. Poebel, foto n: 27875 do Oriental Institute, citado por GELs, 1976, p. 102.

A progressiva simplificaçåo dos traços em escritas primitivas, exemplificada pela evolução histórica da escrita cuneiforme, está presente tanto naqueles sistemas que nảo ultrapassaram a expressão do sentido ou significado da mensagem a ser registrada como naqueles que se desenvolveram posteriormente em sistemas plenos de escrita, com recursos limitados ou plenamente desdobrados dá expressão dos conteúdos lingüísticos. 


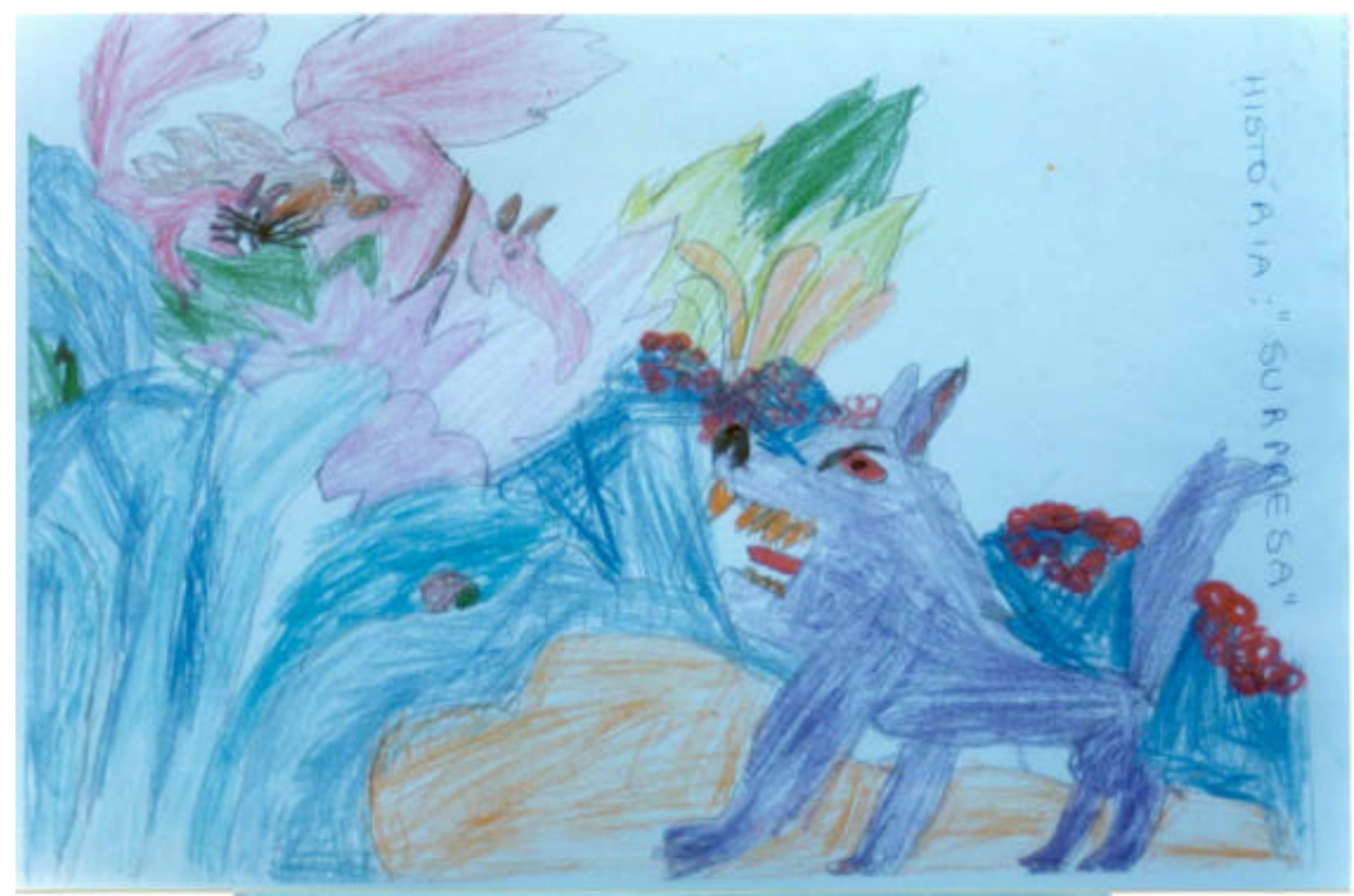

\section{(PRODUÇÃO DE JO.)}

Através da leitura do trabalho de Reily que traz vários casos de savants, encontramos um que nos fez lembrar o Jo. por vários aspectos; no grupo de discussão da pós - graduação em Psicologia coordenado pela professora Dra. Luci Banks Leite (FE/UNICAMP) discutimos este assunto e pareceu-nos provável que o aluno Jo. seja um savant.

Vamos ao caso: Richard Wawro (REILY, 1994: 44) se apóia em imagens vistas em livros ou na televisão, ou desenha de memória cenas de paisagens vistas com seus binóculos. Jo. se apoia em imagens vistas em livros, cadernos, cartazes e em cenas presentes em sua vida diária. Wawro apresenta alguns comportamentos autistas: obsessão por rotina fixa, distanciamento social, gestos bizarros, comportamento ritualístico e atraso na evolução da linguagem. Em Jo., percebemos um comportamento ritualístico; por exemplo, quando ele vai desenhar, primeiro aponta todos os lápis de cor que vai usar, coloca em ordem crescente na mesa e organiza seus objetos em uma ordem específica; se alguém muda algum lápis ou objeto de posição, ele pára imediatamente e recoloca no local certo. É um aluno de pouca amizade, quase sempre está sozinho concentrado em sua atividade e no intervalo fica correndo ao redor do pátio se divertindo sozinho. Não percebemos uma obsessão por rotina 


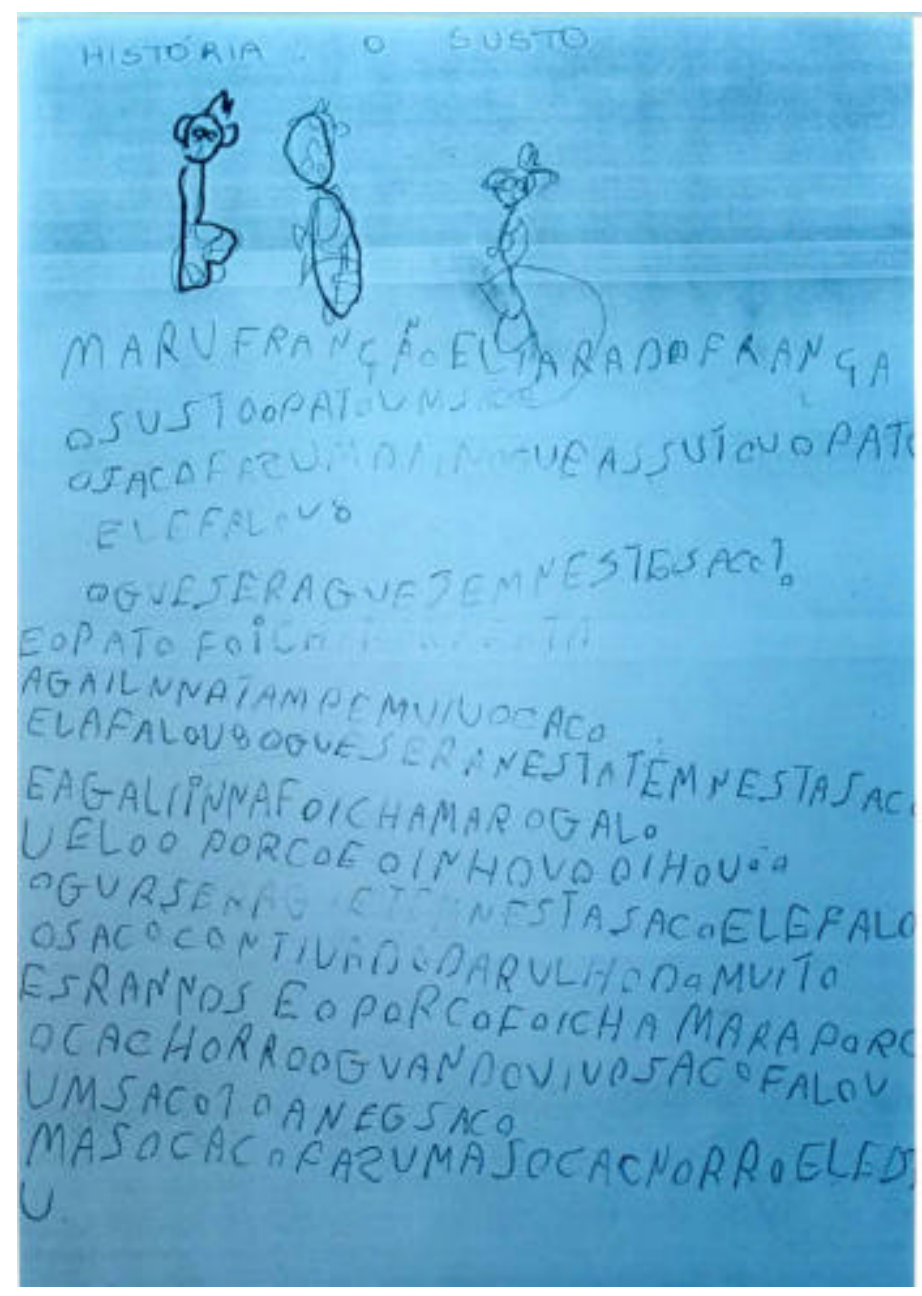

(PRODUÇÃO DE LU.)

fixa, mas uma certa tendência que vai nesse sentido: sempre quando chegava na sala, colocava sua mochila na mesa e ia pegar um gibi para folhear. Em relação a sua linguagem verbal, esta é prejudicada principalmente quando fica nervoso; nessas ocasiões apresenta um ataque de gagueira.

Em sua página 125 , a autora coloca os aspectos ausentes da produção savant, aspectos estes ausentes também na produção de Jo.: não se encontram instâncias de imagens abstratas; ausência de conteúdo de origem pessoal claramente simbólica, reveladora do mundo interior; não se evidencia humor, caricatura, piadas ou jogo de imagens incompatíveis; não se encontram imagens de sonho ou alucinação, nem imagens que transmitem medo ou terror; não se apresentam metáfora e analogias, nem tampouco imagens de origem religiosa.

Já em relação aos aspectos comuns na produção dos savants, dos dez itens, sete foram encontrados na produção de Jo. e dos outros três, um não foi observado, os aspectos são: surgimento "espontâneo" (sem treinamento prévio) da habilidade artística; desenho de temática figurativa; agilidade na execução; ausência de padrões decorativos; evidência de uso de regras; restrição na seleção de temas e técnicas; representação de memória; em relação a este último aspecto, temos algumas 
dúvidas, pois o Jo. gosta muito de copiar, porém, em muitas ocasiões faz desenhos de memória.
A seguir, colocaremos um desenho feito por Richard Wawro.

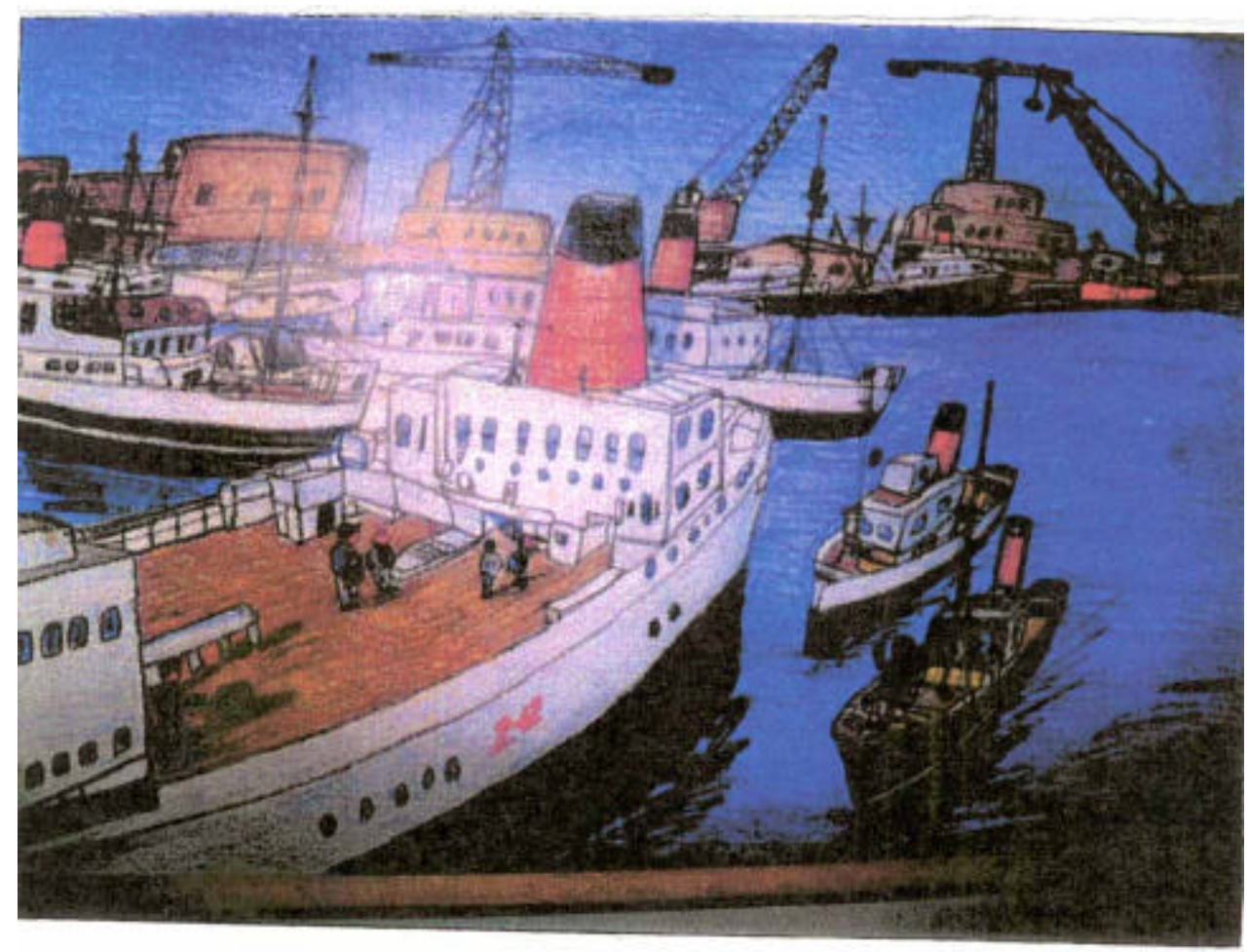

\section{CONSIDERAÇÕES FINAIS.}

O estudo do desenho infantil já é um tema bastante explorado na literatura, algo que vem sendo tratado de longa data. $\mathrm{O}$ original de LUQUET é de 1927 e o de VYGOTSKY (1987) é de 1930. Então, muitos devem se perguntar: por que será que vão pesquisar algo que já está tão falado?

Pensamos que o que teve de original em nosso trabalho foi a abrangência da questão, como muito se tem estudado no desenho de crianças ditas "normais", acreditamos que muito há, ainda, a se pesquisar no desenho e na produção artística de crianças com "problemas". Nós escolhemos os deficientes mentais, ou melhor, alunos de uma sala especial de uma escola regular e como pudemos notar, Reily já deu início a uma pesquisa nessa área.

No começo do trabalho não nos interessávamos pela questão das fases e estágios na evolução do desenho, esse interesse só veio a tona quando percebemos que tínhamos algo a discutir em relação a essa evolução relacionada às crianças deficientes. Acreditamos que os estágios podem dar indicações interessantes do que se pode esperar das produções da criança. Entretanto, não se deve utilizar esses estágios como meio de rotular as crianças, nem tampouco de prever uma futura evolução.

Enquanto aluna do curso de Pedagogia da Universidade Estadual de Campinas, sinto que esses dois anos que 
venho me relacionando com alunos deficientes mentais trouxe uma contribuição muito importante para nossa pesquisa e que não esperávamos:

* a quebra de preconceitos, pois a grande maioria da sociedade percebe os deficientes mentais como pessoas "idiotas" e sem capacidades; contudo, essa classe especial nos mostrou a grande diversidade existente nesse grupo e, como através de trocas em diferentes níveis, várias habilidades e capacidades pouco evidentes em uma primeira abordagem, têm a possibilidade de surgir.

* decorrente do anterior, torna-se evidente que mesmo dentro de uma classe especial, há uma multiplicidade de casos, razão pela qual não podemos colocar todos os alunos dentro de um mesmo "pacote"; cada aluno deficiente como, também, cada ser humano tem suas singularidades e possibilidades que só as interações sociais e a convivência nos permite perceber.

\section{REFERÊNCIAS BIBLIOGRÁFICAS.}

AZENHA, $M^{a}$ da G. (1995) Imagens e letras: Ferreiro e Luria duas teorias psicogenéticas. São Paulo: Editora Ática S.A.

LUQUET, Georges - Henri (1969) O desenho infantil. Barcelos: Companhia Editora do Minho. (original: 1927) Tradução: Maria Teresa Gonçalves de Azevedo.

MEREDIEU, Florence de (1974) O desenho infantil. São Paulo: Editora Cultrix. p. 01-66.

REILY, Lúcia H. (1986) Atividades de artes plásticas na escola: hoje é meu dia, dona aula de artes? São Paulo: Pioneira. p. 01-36

. (1990). Nós já somos artistas: estudo longitudinal da produção artística de pré - escolares portadores de paralisia cerebral. Dissertação de Mestrado. São Paulo: USP - IP.

. (1994) Armazém de imagens: estudo de caso de jovem artista portador de deficiência múltipla. São Paulo: USP Tese de Doutorado (IP).

SILVA, Silvia M. C. (1993). Condições sociais da constituição do desenho infantil. Dissertação de Mestrado. Campinas: UNICAMP.

VYGOTSKY, Lev. S. (1987) Imaginación y el arte en la infancia. México: Hispanicas. (editado em 1930)

\section{(1993) Pensamento e}

linguagem. São Paulo: Martins Fontes. p. 13-21. Tradução: Jefferson Luiz Camargo.

WIDLÖCHER, Daniel. ( 1971) Interpretação dos desenho infantis. Rio de janeiro: Vozes p. 07-115 (Original: 1965)

In: WALLON, PH.; CAMBIER, A. \& ENGELHART, D. (1995) El dibujo del niño. México: Siglo veintiuno editores. Prefácio: p. 07-11. (edição original, 1990).

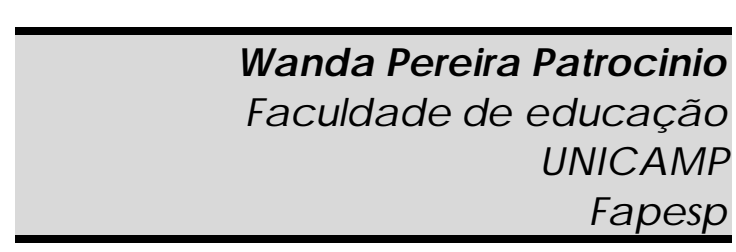

